\title{
Peranan Perusahaan Keagenan terhadap Pengoperasian Kapal Niaga: Studi Kasus
}

\author{
Mohammad Shohibul Anwar ${ }^{a^{*}}$, Dedi Nuryaman ${ }^{\mathrm{b}}$ \\ a,b Akademi Maritim Suaka Bahari Cirebon \\ a*Email: shohibul.anwar@akmicirebon.ac.id \\ bEmail: dedi.nuryaman@akmicirebon.ac.id
}

\begin{abstract}
ABSTRAK
Indonesia disebut dengan negara maritim, karena sebagian wilayahnya merupakan perairan. Dengan begitu, Indonesia mempunyai kesempatan menjadi negara poros maritim di Asia bahkan di dunia. Kesempatan tersebut harus segera direalisasikan dengan maksimal, yaitu dengan memaksimalkan kegiatan di pelabuhan dengan baik. Kegiatan untuk mempermudah aktivitas perkapalan baik bongkar muat, ekspedisi laut, dan lain sebagainya diperlukan peranan keagenan. Salah satunya peranan keagenan PT. Indo Dharma Transport yang berada di Surabaya. Perusahaan tersebut mempunyai peranan dalam pengoperasian kapal niaga yang berada di wilayah Surabaya. Tujuan penelitian ini adalah untuk mendeskripsikan peranan perusahaan keagenan terhadap pengoperasian kapal niaga di wilayah Surabaya. Penelitian ini merupakan jenis penelitian kualitatif dengan menggunakan metode observasi, wawancara, dan dokumentasi. Melalui penelitian ini, ditemukan kesimpulan bahwa peranan keagenan PT. Indo Dharma Transport Cabang Surabaya memberikan kemudahan dan kelancaran dalam pengoperasian kapal niaga di wilayah Pelabuhan Surabaya.
\end{abstract}

Kata Kunci: peranan keagenan, pengoperasian kapal

\section{ABSTRACT}

Indonesia is called a maritime country because part of its territory is water. That way, Indonesia has the opportunity to become a maritime axis country in Asia and the world. This opportunity must be realized to its full potential, namely by maximizing activities at the port properly. Activities to facilitate shipping activities both loading and unloading, sea expeditions and so on are needed for the benefit of the agency's role. One of them is the role of the PT. Indo Dharma transportation located in Surabaya. This company has a role in the merchant ship wars in the Surabaya area. The purpose of this study is to describe the role of agency companies in the operation of commercial ships in the Surabaya area.This research is a qualitative research using observation, interview and documentation methods. Through this research, it was found that the case of PT. Indo Dharma Transpor Surabaya Branch provides convenience and smooth operation of Commercial Vessels in the Surabaya Port area.

Keywords: agency role, ship operation

\section{PENDAHULUAN}

Indonesia merupakan negara maritim. Negara yang sebagian besar wilayahnya adalah berupa air (laut).
Dengan keadaan tersebut Indonesia harus memiliki strategi dalam memanfaatkan aktivitas yang berkaitan dengan laut, salah satunya ialah aktivitas 
di pelabuhan. Kegiatan di pelabuhan dilakukan banyak instansi yang terkait. Instansi itu seperti administrator pelabuhan, bea dan cukai, imigrasi, kesehatan pelabuhan, ekspedisi muatan kapal laut, perusahaan bongkar muat. Perusahaan pelayaran PT. Indo Dharma Transport sebagai suatu badan perwakilan yang mengurus kebutuhan kapal di pelabuhan. Jadi pemilik kapal mendapat wakilnya di pelabuhan, tempat singgah kapal untuk melakukan suatu kegiatan ini diperlukan karena selalu tidak mungkin untuk menangani semua kapal yang ada di pelabuhan. Terutama apabila kapal berlayar ke seluruh dunia, dengan adanya agen perusahaan pelayaran maka mempermudah kepengurusan segala sesuatu kebutuhan kapal di mana kapal itu singgah. Menurut (Fatah, Sukiman, \& Fathurachman, 2019) menjalin hubungan baik dengan berbagai instansi dalam penanganan kapal merupakan salah satu cara meningkatkan kinerja perusahaan sehingga muncul kepercayaan yang baik antara perusahaan keagenan dengan instansi terkait. Dengan adanya kerjasama dan kepercayaan yang baik juga akan memudahkan perusahaan dalam menangani kapal yang diageni.

Untuk memperlancar kegiatankegiatan di suatu negara maka perusahaan pelayaran menunjuk salah satu perusahaan pelayaran nasional untuk bertindak atas nama perusahaan pelayaran tersebut (principle). Perusahaan pelayaran yang ditunjuk untuk melakukan kegiatan di suatu negara disebut agency, sedangkan badannya dinamakan agen. Agency bukan secara struktural di bawah perusahaan pelayaran yang diageni dan melakukan kegiatan atas nama principle. Kemudian untuk biaya-biaya untuk ditentukan atas persetujuan kedua badan tersebut. Agency tidak hanya menangani satu perusahaan pelayaran tetapi dapat lebih dari satu tergantung dari kemajuan perusahaan tersebut.

https://doi.org/10.46484/db.v2i1.255
Dari hal tersebut, menunjukkan bahwa pelayaran mempunyai peranan yang sangat penting karena hampir sebagian besar kegiatan ekspor dan impor menggunakan jasa perusahaan pelayaran yang mengoperasikan kapal laut. Beberapa keuntungan menggunakan kapal dibanding dengan sarana transportasi lainnya adalah karena memiliki daya angkut yang lebih banyak dengan biaya relatif lebih murah serta risiko yang lebih kecil. Oleh karena itu, kelancaran transportasi laut dengan kapal harus benar-benar dipastikan beroperasi dengan baik (Rubiyanto, 2017).

\section{METODE}

Jenis penelitian yang digunakan dalam penelitian ini adalah kualitatif deskriptif yaitu dengan metode observasi. Menurut Sugiyono (2015 : 204), observasi adalah memperoleh data dengan cara langsung mengadakan pengamatan terhadap suatu obyek dan sambil mengamati, mencatat apa yang telah diamati sejelas-jelasnya. Observasi yang peneliti lakukan bertempat di PT. Indo Dharma Transport Cabang Surabaya. Peneliti melihat dan merasakan secara langsung terkait dengan peranan keagenan PT. Indo Dharma Transport terhadap pengoperasian khususnya di kapal niaga di wilayah Pelabuhan Surabaya. Selanjutnya peneliti melakukan interview. Menurut Sutopo (2002: 72), interview adalah menghimpun data dengan cara mengadakan wawancara langsung terhadap pihak yang bersangkutan dalam pelaksanaan pengoperasian dokumen kapal, kepala bagian dan karyawan pada perusahaan yang bersangkutan. Adapun penggalian data dalam penelitian ini, peneliti melakukan wawancara mendalam dan terstruktur terhadap pimpinan dan pegawai PT. Indo Dharma Transport.

Peneliti melakukan dokumentasi untuk mendapatkan data-data yang belum didapatkan melalui metode observasi dan wawancara. Menurut 
Haris Herdiansyah (2010 : 143), metode dokumentasi adalah salah satu metode pengumpulan data kualitatif dengan melihat atau menganalisis dokumendokumen yang dibuat oleh subjek sendiri atau oleh orang lain oleh subjek.

\section{HASIL DAN PEMBAHASAN}

Keagenan umum adalah perusahaan pelayaran yang ditunjuk oleh perusahaan lain di Indonesia atau perusahaan asing di luar negeri (principal) untuk mengurus segala sesuatu yang berkaitan dengan kepentingan kapal principle tersebut baik kapal milik atau kapal charter yang dioperasikan oleh principle (Kosasih, 2012). Dalam prosedur menunjukkan keagenan, bahwa pemilik kapal atas dasar kepentingan dalam pengoperasian kapal di negara lain atau tempat lain dapat menunjuk agen, pengertian agen digunakan bila pemilik kapal tersebut merupakan perusahaan asing dan agen sendiri harus mempunyai wakil-wakil di pelabuhan. Jika pengoperasian kapal dilakukan hanya satu negara maka tidak diperlukan agen, pemilik kapal mengkoordinir kapal-kapalnya sendiri di pelabuhan dengan membuka kantor cabang pelayaran.

\section{Penunjukan Keagenan}

a. Penunjukan keagenan umum

Menunjuk agen umum (general agent) oleh pemilik kapal atau principle, ada beberapa prosedur dan tata cara penunjukan keagenan antara lain dapat dilakukan dengan cara sebagai berikut :

1) Atas dasar untuk pengoperasian kapal di negara lain, pemilik kapal mengirim seorang wakil untuk mencari, memilih, dan meneliti keberadaan perusahaan-perusahaan di negara tertentu.

2) Wakil pemilik kapal mengadakan penawaran dan mengajukan perjanjianperjanjian yang akan disepakati bersama menyangkut hak dan kewajiban masing-masing pihak.

3) Jika perusahaan tersebut menyetujui segala perjanjian yang diajukan maka wakil pemilik kapal akan menyerahkan surat penunjukan agen untuk segera ditandatangani bersama-sama dengan perjanjian.

4) Menjamin keberadaan perusahaan yang ditunjuk dari kerugian yang disebabkan oleh pailitnya pemilik kapal, maka pemilik kapal memberikan surat jaminan bank.

Jika semua ketentuan tersebut di atas telah disetujui dan dipenuhi oleh kedua belah pihak yang kemudian dituangkan dalam "Agency Agreement", maka perusahaan yang ditunjuk sudah dapat dikatakan sebagai agen, kemudian diterbitkan Letter of Appointment atau surat penunjukan oleh principle dan agen tersebut segera melaporkan kegiatannya kepada badan pemerintah yang bersangkutan agar kapal yang dioperasikan atau yang memasuki wilayah negara dapat melakukan kegiatannya.

Dalam melakukan keagenan liner service, penunjukan keagenan umum berlaku untuk jangka waktu tertentu dan dapat diperpanjang bilamana perlu. Sedangkan dalam melayani tramper service penunjukan keagenan dapat terjadi kapal per kapal dan penunjukan tersebut cukup dengan Letter of Appointment per fax atau per telex.

b. Penunjukan Agen Cabang (Sub Agent)

Sub agen adalah perusahaan angkutan laut nasional atau perusahaan nasional yang khusus didirikan untuk melakukan usaha 
keagenan kapal di pelabuhan atau terminal khusus tertentu yang ditunjuk oleh agen umum (BPKP, 2010). Kepentingan pelayanan dan penanganan kapal baik kapal milik atau kapal keagenan di suatu pelabuhan di luar wilayah kerja agen umum, maka agen umum akan menunjuk sub agent sebagai pelaksana kegiatan keagenannya.

Sub agent merupakan cabang dari agen umum yang berarti antara agen umum dan sub agent mempunyai hubungan terencana. Karena memang keberadaan sub agent ditunjuk untuk membantu atau sebagai pelaksana agen umum, lain halnya dengan sub agent yang merupakan perusahaan lain, sehingga memerlukan penunjukan oleh agen umum.

2. Syarat-Syarat Menjadi Agen Pelayaran

Agen pelayaran adalah sebuah badan usaha yang bergerak dalam kegiatan atau aktivitas kapal atau perusahaan pelayaran, syarat-syarat menjadi agen pelayaran adalah sebagai berikut:

a. Merupakan Badan Usaha Milik Negara (BUMN) termasuk Badan Hukum Milik Daerah yang merupakan usaha di bidang angkutan laut, atau Badan Hukum Indonesia yang berbentuk Perseroan Terbatas (PT) yang didirikan khusus untuk usaha tersebut;

b. Memiliki dan atau menguasai sekurang-kurangnya sebuah kapal yang laik laut berbendera Indonesia;

c. Bagi perusahaan pelayaran yang bergabung antara perusahaan pelayaran nasional dengan perusahaan pelayaran asing wajib menguasai sekurang-kurangnya sebuah kapal yang laik laut berbendera asing;

d. Mempunyai Nomor Pokok Wajib Pajak (NPWP); e. Mempunyai Surat Izin Usaha Perdagangan (SIUP);

f. Mempunyai surat izin operasional yang dikeluarkan oleh syahbandar setempat.

Mempunyai surat penunjukan keagenan yang diberikan oleh pemilik kapal atau perusahaan pelayaran.

3. Tugas dan Tanggung Jawab Keagenan

Menurut (Suwarno, 2011) terdapat beberapa tugas pokok keagenan kapal, yaitu memberikan pelayanan operasional kapal-kapal principal, memonitor perkembangan muatan, penanganan terhadap kapal dan muatannya, penyelesaian masalah claim sesuai dengan manual atas barang kurang atau muatan rusak, lalu meneruskannya kepada principal sepanjang memenuhi persyaratan dan membayar claim tersebut setelah mendapat persetujuan dari principal, dan pelayanan claim yang menyangkut keputusan owner's representative.

Melaksanakan tugas dan tanggung jawab keagenan perusahaan pelayaran yang ditunjuk harus berpedoman pada instruksi dari principle. Keuntungan perusahaan pelayaran tidak hanya tergantung dari banyaknya kapal yang dimiliki dan muatan maupun penumpang yang dapat diangkut saja, melainkan banyak kemungkinan yang terjadi misalnya saja keberadaan kapal yang terlalu lama berada di pelabuhan yang disebabkan oleh kegiatan bongkar muat mengalami hambatan.

Karena keberadaan kapal yang terlalu lama di pelabuhan merupakan kerugian. Hal ini disebabkan oleh karena waktu yang dibutuhkan melampaui target waktu yang ditentukan, kerugian ini karena dari hari ke hari kapal akan mengeluarkan tidak sedikit biaya yaitu keperluan bahan bakar, air tawar, serta keperluan awak kapal. 
Kapal selama berada di pelabuhan, tidak hanya melakukan kegiatan bongkar muat saja tetapi juga harus menyelesaikan dokumendokumen yang berkenaan dengan masalah itu dan juga mengurusi dokumen-dokumen kapal yang habis masa berlakunya.

Pengusaha kapal akan selalu berusaha bagaimana agar kapal tidak terlalu lama berada di pelabuhan dan dengan waktu yang singkat. Diusahakan dalam bongkar muat dapat dilakukan dengan waktu yang cepat dan singkat. Pengurusan dokumen juga diusahakan dapat dikerjakan secepat mungkin. Oleh sebab itu, agen harus bekerja secara cepat dan efisien dalam mengurus dokumen. Informasi adalah hal penting dalam aktivitas perusahaan pelayaran. Informasi yang terkini akan menjadi kunci sukses agen dalam proses aktivitasnya. Inilah peran agen dalam menerima dan memberikan informasi sehingga dapat memaksimalkan pelayanan dan meminimalisir hambatan yang terjadi di lapangan (Komalasari, 2020). Hal tersebut di atas merupakan aktivitas perusahaan pelayaran selaku agen yang menangani segala kebutuhan kapal atas perintah dan petunjuk dari pemilik kapal.

4. Tugas dan Kewajiban Agen Pelayaran

Dimulai dengan penunjukan kepada perusahaan pelayaran sebagai agen oleh principal (pemilik atau operator) kapal-kapal asing yang dikukuhkan dalam "Agency Agreement" sebelum kapal tiba principal memberitahukan akan kedatangan kapalnya dan jumlah muatan yang perlu ditangani kepada General Agent kemudian General Agent akan memerintahkan cabang sebagai pelaksana untuk pelayanan kapal dan muatannya dari kapal principal. Melaksanakan tugas operasinya (husbanding) maka PT. Indo Dharma Transport cabang
Surabaya sebagai sub agent harus menghayati bahwa tugas tersebut adalah merupakan bagian utama dari produk jasa perusahaan, yang menjadi tanggung jawab bersama untuk terus ditingkatkan mutu pelayanannya terhadap semua principal atau customer perusahaan pelayaran PT. Indo Dharma Transport. Untuk itu PT. Indo Dharma Transport cabang Surabaya telah menjalin hubungan kerja dengan Port Authority dan instansi lain setempat dengan menguasai segala prosedur dan pelayanan yang berlaku.

5. Kedatangan Kapal
a. Informasi
Perencanaan

Kedatangan Kapal

Kantor pusat secara reguler setiap bulannya memberikan jadwal rencana kunjungan kapal atau Monthly Sailing Schedule dari masing-masing liner service maupun tramper service yang akan memasuki pelabuhan Surabaya.

Selambat-lambatnya tujuh hari sebelum tanggal rencana kapal tiba di Pelabuhan Tanjung Perak Surabaya, PT.Indo Dharma Transport cabang Surabaya telah menerima pemberitahuan kedatangan kapal disertai kelengkapan dokumen dan informasi yang diperlukan antara lain:

1) Ships Particular;

2) Port of Call list;

3) Cargo Manifest atau Stowage Plan;

4) Crew list;

5) Tanda terima oleh Dirjen Perla atau Pemberitahuan Kedatangan Kapal Asing (PKKA) di Jakarta;

6) Letter of Appointment dari pusat;

7) Permintaan pemilik kapal atau master kapal;

8) Pemberitahuan khusus lainnya;

9) Cable Master. 
b. Kedatangan Kapal

Perusahaan pelayaran dalam hal ini PT. Indo Dharma Transport Cabang Surabaya menerima berita tentang kedatangan kapal, minimal satu hari sebelum kapal tiba harus sudah mengajukan permohonan dan pamberitahuan kepada instansi-instansi yang terkait di Pelabuhan Tanjung Perak Surabaya yaitu:

1) Syahbandar Pelabuhan

Tanjung Perak Surabaya.

Dalam pemberitahuan ini dilampiri dengan pemberitahuan kedatangan kapal asing dari Jakarta yang telah disahkan. Kapada Syahbandar kita mengajukan izin gerakan kapal di Pelabuhan Tanjung Perak Surabaya;

2) PT Pelindo III Cabang Tanjung Perak Surabaya, pemberitahuan umum ini dilampiri dengan pemberitahuan umum dari Syahbandar yang telah disetujui. Kepada PT. Pelindo III mengajukan permohonan jasa labuh, pandu, tunda dan Tambat;

3) Petugas Imigrasi Pelabuhan Tanjung Perak Surabaya;

4) Petugas Karantina (kesehatan) Pelabuhan Tanjung Perak Surabaya;

5) Petugas Bea dan Cukai Pelabuhan Tanjung Perak Surabaya.

Selain kepada instansi pemerintah tersebut juga pemberitahuan kepada shipper atau consignee. Menurut (Sasono, 2012) shipper (pengirim) adalah mereka yang bertindak selaku pengirim barang milik cargo owner untuk dikapalkan melalui suatu perjanjian pengangkutan laut.
Sedangkan, consignee (penerima) adalah mereka yang berkedudukan sebagai penerima barang muatan yang tercantum dalam suatu konosemen di pelabuhan bongkar (port of discharging). Kemudian cabang PT. Indo Dharma Transport atas nama principle dapat mengeluarkan Surat Penunjukan Kerja (SPK) kepada Pelaksana Bongkar Muat (PBM) atau Stevedor untuk melakukan kegiatan bongkar muat dari setiap kapal yang diageni kecuali ditentukan lain apabila PBM telah ditunjuk oleh pemilik barang. PBM yang ditunjuk harus melaksanakan misi PT. Indo Dharma Transport services yaitu agar tercapai kecepatan atau memperpendek waktu kapal tinggal di pelabuhan. Mengajukan permintaan tempat sandar, kita menyerahkan pemberitahuan kedatangan kapal yang telah disetujui oleh syahbandar atau Adpel kepada Sub Dinas Pangkalan untuk rencana tambat dan pre rencana tambat yang kemudian dirapatkan bersama dengan PBM yang telah ditunjuk di Pusat Pelayanan Satu Atap (PPSA). Nantinya akan diputuskan dan ditetapkan kapal-kapal yang mana berhak mendapatkan tempat sandar terlebih dahulu sesuai dengan ketentuan yaitu first come first service.

c. Kapal Tiba dan Bersandar

Menurut (Lasse, 2014) clearance in atau kapal masuk berawal dari inisiatif perusahaan pelayaran atau agen yang menerima informasi dari kapal berupa master cable atau berita dari stasiun radio operasi pantai. Selanjutnya, 
pelayaran atau agen yang bersangkutan menyampaikan aplikasi pelayanan jasa sesuai tugas pokok dan fungsi masingmasing kepada operator pelabuhan atau terminal untuk fasilitas kapal dan barang, kemudian instansi bea cukai, imigrasi, karantina pelabuhan, dan untuk personel pandu bandar dan kapal tunda. PT. Indo Dharma Transport menugaskan seorang boarding officer di lapangan untuk memeriksa kesiapan pelayanan jasa dari PT. Persero yaitu pandu, tunda, dan fasilitas dermaga, serta kesiapan stevedor sebelum kapal tiba atau sandar. Sesaat setelah kapal sandar kemudian boarding officer menemui kapten kapal untuk mengambil dokumen kapal dan meminta informasi yang diperlukan. Kemudian dokumen tersebut segera dilaporkan dan diserahkan kepada instansiinstansi yang terkait atau sering disebut clearance in yaitu:

1) Syahbandar

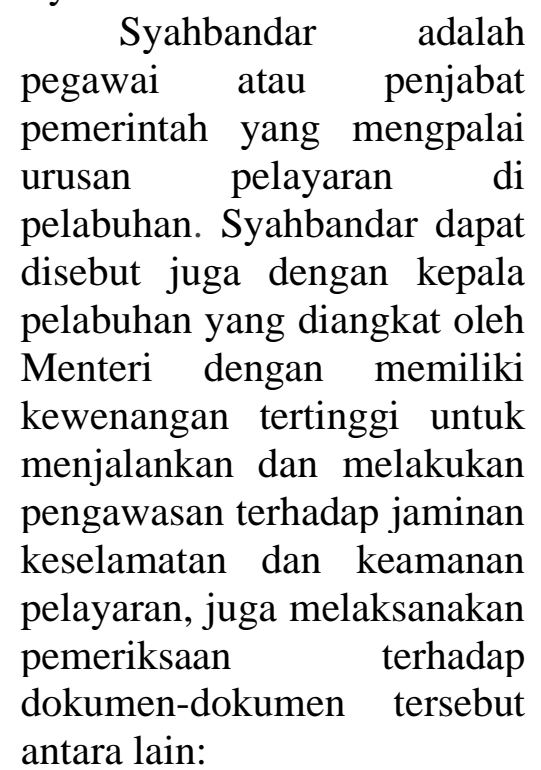

a) Port Clearance ( Surat Izin Berlayar dari pelabuhan sebelumnya)

Surat Persetujuan Berlayar adalah dokumen negara yang dikeluarkan oleh Syahbandar kepada setiap kapal yang akan berlayar meninggalkan pelabuhan setelah kapal memenuhi persyaratan kelaiklautan kapal dan kewajiban lainnya. Dokumen ini menjadi begitu penting karena menyangkut kelancaran operasional kapal serta keselamatan kapal, nakhoda, maupun awak kapal (Mandala, Setyadiharja, Jefri, Renaldi, \& Mulyani, 2016);

b) Indonesia Health Book (Buku Kesehatan);

c) Registration Certificate (sertifikat kapal dimana dibuat);

d) Minimum Safe Manning (Daftar Crew Perwira);

e) Derating Certificate

f) Internasional Tonnage (Garis muat/lambung muat sampai tahun berapa);

g) Cargo Ship Safety Contruction Certificate;

h) Certificate Of Inspection;

i) International Load Line Certificate;

j) International Oil Pollution Prevention Certificate;

k) Life raft Certificate;

1) Cargo Ship Safety Equipment Certificate.

2) Petugas Imigrasi

Mengadakan pemeriksaan terhadap dokumen antara lain:

a) Crew List;

b) Nil List (Daftar penumpang selain crew);

c) Passenger List (Dafar penumpang);

d) Paspor atau Buku Pelaut.

3) Petugas kesehatan pelabuhan

Instansi ini mengadakan pemeriksaan terhadap: 
a) Indonesia Health Book (Buku kesehatan);

b) Vaccination Book (Keterangan bebas vaksinasi);

c) Maritime Declaration (Deklarasi laut yang menyatakan bahwa crew bebas dari penyakit yang dilarang oleh pemerintah);

d) Pemeriksaan CI (Port health clearance);

e) Pemeriksaan karantina kapal.

4) Dinas Bea dan Cukai

Semua barang yang masuk ke wilayah Indonesia yang berasal dari luar negeri wajib dilaporkan ke Dinas bea cukai dengan dilampiri dokumen antara lain:

a) cargo manifest;

b) personal effect;

c) bonded store List dan ship store list;

d) port of call list.

5) Laporan ke kantor pusat

Selain ke instansiinstansi tersebut, PT. Indo Dharma Transport juga mengirim laporan kedatangan kapal baik per telex atau fax ke kantor pusat yang menginformasikan tentang:

a) Waktu kapal tiba atau pandu naik kapal;

b) Waktu kapal sandar atau tambat;

c) Keadaan kapal waktu tiba;

d) Waktu kegiatan bongkar atau muat dimulai;

e) Waktu ditandatangani Notice of Readiness oleh master (untuk kapal tramper);

f) Perkiraan waktu selesai bongkar atau muat;

g) ETD (perkiraan waktu berangkat); d. Mengurus dan memonitor kapal selama di Pelabuhan

Selama kapal melaksanakan kegiatan bongkar atau muat, agen pelayaran melaporkan kegiatan maupun keperluan kapal kepada pemilik atau penyewa sebagai berikut:

1) Daily Report

PT. Indo Dharma Transport menempatkan petugas operasi yag secara regular setiap hari memonitor kegiatan Cargo Operation (Daily report) misalnya dengan mengunjungi kapal dan PBM serta mengirim daily report secepatnya per telephone atau fax ke general agent di Jakarta paling lambat jam 10.00 WIB. Daily Report ini menginformasikan hal-hal sebagai berikut:

a) working gang pershift;

b) productivity per palka Pershift;

c) total Productivity;

d) balance cargo atau tonnage;

e) muatan yang telah dibongkar atau muat;

f) alasan dari keterlambatan waktu (delay times).

PT. Indo Dharma Transport berperan aktif dalam mengatasi hambatan cargo operation bersama pihak kapal maupun stevedor serta selalu menghubungi shipper atau consignee setiap hari.

Apabila terjadi kerusakan barang atau kerusakan lainnya terhadap kapal yang diakibatkan oleh kegiatan bongkar muat maka PT. Indo Dharma Transport membantu pihak kapal yang diageninya untuk 
mencarikan surveyor atas dasar permintaan tertulis dari master atau master datang langsung ke kantor dan menyatakan bahwa segala biaya dibebankan kepada owner atau kapal.

2) Pengurusan keperluan kapal dan awak kapal

Mengurus keperluan kapal merupakan kegiatan sehari-hari pada PT. Indo Dharma Transport cabang Surabaya dalam hal ini harus sesuai dengan ketentuan yang berlaku, seperti kapal yang akan meminta tambahan bahan bakar dan air tawar terlebih dahulu mengirim surat permintaan pengisian bahan bakar dan air tawar, untuk bahan bakar Pertamina dan Pelindo untuk air tawar. Dengan ketentuan setelah kapal bersandar baru dimulai pengisian, untuk pengurusan awak kapal PT. Indo Dharma Transport tidak menyediakan fasilitas (akomodasi) melainkan menyediakan alat transportasi untuk kepentingan crew kapal.

3) Pengurusan perbaikan dan perawatan kapal

Saat kapal mengalami kebocoran, langkah yang diambil PT. Indo Dharma Transport segera mengajukan permohonan izin las ke syahbandar dan pelaksanaan di kerjakan oleh pihak kapal setelah mendapat izin dari syahbandar setempat.

4) Statement of Fact Agen PT. Indo Dharma Transport membuat Statement of Fact berdasarkan time sheet daily report dari PBM. Statement of Fact menginformasikan antara lain:

a) nama kapal;

b) kebangsaan kapal;

c) pemilik kapal atau principle;

d) nama nakhoda;

e) tanggal tiba di terminal pandu untuk Surabaya di Karang Jamuang;

f) tanggal dan jam pandu naik ke kapal;

g) tanggal dan jam memasuki area pelabuhan;

h) waktu tambat di dermaga;

i) tanggal dan waktu penandatanganan Notice of Readiness (NOR);

j) pelabuhan singgah terakhir dan pelabuhan selanjutnya;

k) selesai bongkar atau muat;

1) total cargo yang di bongkar atau muat;

m) waktu berlayar kembali;

n) kondisi pada saat kapal tiba dan berangkat yang menyangkut tonnage atau draftnya.

Keterangan ini ditandatangani oleh master dan diketahui oleh agen pada saat kapal akan berlayar dan keterangan ini kemudian dikirimkan ke kantor pusat. Sebelum kapal meninggalkan pelabuhan semua dokumen Mate Receipt harus sudah ditandatangani oleh mualim satu.

5) Keberangkatan kapal

Agen membuat Sailing

Order (perintah berlayar) paling lambat lima jam sebelum kegiatan bongkar muat selesai untuk disampaikan kepada master dan chief officer sebagai 


tembusannya. Petugas
operasi semakin sering
memonitor kelancaran cargo
handling untuk menghadapi
kemungkinan adanya
permintaan berlayar dari
master atau permintaan
pandu dan tunda. Setelah
kegiata bongkar muat
selesai petugas operasi
segera melaksanakan
clearance out kepada
instansi yang terkait yaitu:

a) Imigration Clearance.

Memintakan Stamp

Out pada paspor dan terlampir Crew List stamp out.

b) Syahbandar Clearance

Memintakan surat
izin Berlayar dan
sertifikat asli diambil
kembali dan
dikembalikan ke kapal.

c) Bea dan Cukai

Memasukkan

dokumen muatan pada kantor bea dan cukai agar barang tersebut telah legal untuk dikirim ke luar negeri.

d) Kantor Kesehatan

Pelabuhan

Meminta Port Health Cearance Out/PHQC

e) Dinas Kepanduan

Mengurus

permohonan penggunaan jasa yaitu jasa tunda dan pandu yang akan mengantar kapal sampai batas perairan pelabuhan.

Setelah selesai clearance out surat-surat dikembalikan kepada master berikut surat muatannya. Petugas operasi yang telah dipercaya ditugaskan untuk mengunjungi kapal menjelang waktu keberangkatan untuk meyakinkan segala

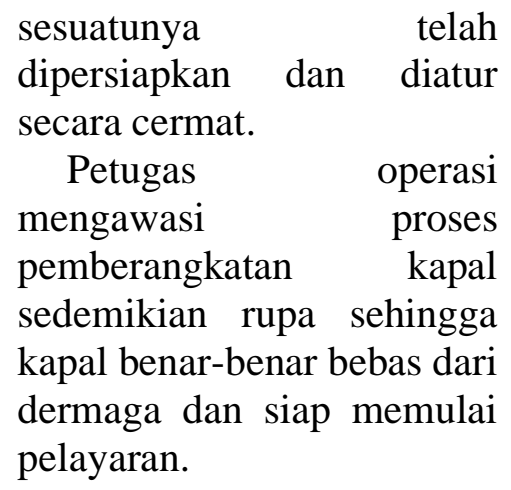

Segera setelah kapal berangkat, PT.Indo Dharma transport harus mengirimkan departure report kepada kantor pusat dan tembusannya ke bagian keuangan departure report ini berisi:

a) keadaan kapal pada saat berangkat;

b) muatan yang telah dimuat atau dibongkar;

c) ETA Next Port (perkiraan waktu tiba pelabuhan selanjutnya);

d) master Request for Next Port (permintaan nakhoda untuk pelabuhan selanjutnya).

\section{Pelayanan Terhadap Cargo Document \\ Tugas PT. Indo Dharma} Transport bukan hanya sekedar sandar atau memberangkatkan kapal tetapi juga memberikan pelayanan terhadap kelengkapan dokumen muatan yang diangkut kapal yaitu:

a. Shipping Instruction.

Hasil nyata dari kegiatan seles and marketing adalah pembukuan muatan oleh para pengirim barang (shipper) kepada perusahaan pelayaran dalam hal ini adalah PT.Indo Dharma Transport Cabang Surabaya.

Pembukuan muatan tersebut dilakukan oleh shipper dengan menyerahkan Shipping Instruction (SI) yang secara terperinci menyebutkan hal-hal sebagai berikut: 
1) nama kapal pengangkut;

2) pelabuhan bongkar dan tempat atau kota penyerahan;

3) kontrak pengapalan (prepaid atau collect);

4) alamat dan nama pengirim atau penerima;

5) notify party (pihak yang diberitahui);

6) net atau gross weight cargo;

7) Jumlah dan merek barang;

8) nomor container apabila muatan container;

9) nomor segel (seal);

10) keterangan barang.

Shipping Instruction ini sangat penting karena merupakan dasar bagi pembuatan dokumen kapal atau Bill of Lading $(B / L)$

b. Loading List

SI (Shipping Intruction) dari shipper, kemudian dibuat Loading List yaitu suatu daftar yang menerangkan jumlah, berat, merek, dan pelabuhan bongkar dari barang-barang yang akan dimuat. Loading list ini harus diserahkan kepada master pada saat kapal datang dan juga di serahkan kepada PBM yang akan melaksanakan kegiatan bongkar atau muat.

Apabila kemudian ada muatan tambahan dan disetujui oleh master untuk dimuat maka segera ditambahkan ke loading list.

c. Mate Receipt

PT.Indo Dharma Transport telah mempersiapkan (Mate Receipt) M/R sesuai dengan SI (Shipping Instruction) masingmasing untuk ditandatangani oleh mualim 1 setelah barang dimuat di kapal hendaknya $\mathrm{M} / \mathrm{R}$ ini mencantumkan hal-hal sebagai berikut:

1) Nama kapal yang mengangkut muatan tersebut;

2) Nama barang

3) Jumlah kolli;
4) Net atau Bruto dan ukuran barang;

5) Jenis dan merek barang;

6) Nomor Letter of Credit (L/C)

7) Nomor container apabila muatan container;

8) Pelabuhan muat atau bongkar;

9) Nama shipper dan consignee

Mate Receipt ini ditanda tangani oleh Mualim I setelah barang berada di atas kapal ( ship on board)

d. Bill of Lading

Bill of Lading adalah suatu tanda terima penyerahan barang yang dikeluarkan oleh perusahaan pelayaran sebagai tanda bukti pemilikan atas barang yang telah dimuat di atas kapal laut oleh shipper untuk diserahkan kepada consignee. Bill of Lading merupakan alat bukti penerimaan sekaligus penyerahan hak milik atas barang sebagai pelaksanaan suatu transaksi antara eksportir dan importir (Hutabarat, 1996).

1) Tata Cara Pembuatan Bill of Lading

Bill of Lading harus dibuat berdasarkan SI dengan berpedoman pada M/R karena dokumen ini sangat berharga, maka pembuatannya harus dilakukan dengan baik, lengkap dan benar, serta hanya ditandatangani oleh pejabat cabang yang telah diberi kuasa. Terdapat koreksi baik atas permintaan secara tertulis dari shipper maupun kesalahan dalam pengetikan, maka di depan atau di belakang dari angka atau huruf yang diperbaiki itu wajib diberikan stempel correction dan diparaf oleh pejabat yang diberi kuasa. Jika terdapat koreksi terhadap B/L telah dilakukan 3 (tiga) kali maka $\mathrm{B} / \mathrm{L}$ tersebut harus diganti dengan 
yang baru dan yang lama dimusnahkan. Koreksi B/L tidak boleh dilakukan pada kolom freight dan perjanjian pembayaran.

Koreksi yang

dilakukan terhadap B/L yang sudah dikirim harus diterbitkan $\mathrm{B} / \mathrm{L}$ correction dan dikirim ke pelabuhan tujuan serta kopinya ke bagian keuangan. Untuk Break Bulk Cargo tanggal $\mathrm{B} / \mathrm{L}$ harus sama dengan tanggal pemuatan yang dicantumkan dalam SI dan apabila muatan container dapat disesuaikan dengan tanggal stacking di PT. Terminal Peti Kemas Surabaya atau Pemberitahuan Ekspor Barang (PEB) yang telah di fiat muat Kepala Hanggar Bea dan Cukai.

Satu hal yang sangat penting sebagai dasar kekebalan pengangkut dalam masalah klaim yaitu dicantumkan " Said To Container ", maksudnya pengangkut tidak tahu isi dari container yang diangkut misal 1 X 20' container Said To Container (STC) dan "Shipper Load ", Count and seal ", maksudnya shipper yang memuat barang ke container (stuffing) menghitung dan menyegel, sehingga pengangkut tidak mengetahui isi dan jumlah barang tersebut sehingga tidak bertanggung jawab terhadap isi container tersebut.

2) Tata cara penyerahan Bill of Lading

Penyerahan $\mathrm{B} / \mathrm{L}$ pada shipper hanya dapat dilakukan setelah persyaratan sebagai berikut terpenuhi antara lain:

a) Barang-barang yang tercantum dalam $\mathrm{B} / \mathrm{L}$ telah benar-benar dimuat di atas kapal atau dengan bukti mate receipt telah ditandatangani oleh mualim I.

b) Freight dan biaya lainnya harus sudah dibayar di pelabuhan pemuatan apabila "freight prepaid" Setelah kedua persyaratan terpenuhi maka $\mathrm{B} / \mathrm{L}$ dapat diambil oleh shipper untuk diserahkan ke consignee.

Selain itu juga ada cara lain yaitu sureender $\mathrm{B} / \mathrm{L}$, dimana sureender adalah $\mathrm{B} / \mathrm{L}$ original masih berada di pelabuhan pemuatan dan eksportir cukup mengetahui atau mengendorsement kemudian dikembalikan lagi ke perusahaan pelayaran yang membuat $\mathrm{B} / \mathrm{L}$ tersebut dan perusahaan pelayaran tersebut memberitahu ke kantor cabang pelabuhan tujuan untuk mengeluarkan surat kuasa pengambilan barang kepada penerima barang.

\section{e. Cargo Manifest}

Cargo Manifest suatu dokumen yang menerangkan semua nama barang, jenis, berat, dan jumlah serta merek. Semua keterangan yang dicantumkan di dalam cargo manifest dibuat berdasarkan $\mathrm{B} / \mathrm{L}$ dan diserahkan kepada Mualim I sebelum kapal meninggalkan pelabuhan dan diserahkan juga kepada principal dan kantor pusat.

Hal ini harus mendapat perhatian utama dari cabang, karena dokumen tersebut 
merupakan pelindung barang yang berada di atas kapal.

f. Freight Manifest

Dokumen ini menerangkan besar kecilnya uang tambahan yang harus dibayar oleh pengirim barang. Di dalam freight manifest harus disebutkan besarnya freight dan biaya tambahan. Freight manifest merupakan dokumen rahasia yang hanya dikirimkan kepada principle dan kantor pusat (General Agent)

Semua dokumen-dokumen tersebut di atas merupakan tanggung jawab agen perusahaan pelayaran selaku wakil dari principle, yang harus diselesaikan sebelum kapal meninggalkan pelabuhan.

\section{SIMPULAN}

Dari pembahasan tersebut di atas dapat disimpulkan bahwa penunjukan keagenan dilaksanakan setelah agency agremeent disepakati kedua belah pihak, untuk PT.Indo Dharma Transport Cabang Surabaya penunjukan keagenannya melalui general agen di Jakarta.

Tugas dan tanggung jawab agen yang meliputi aktivitas, tugas dan tanggung jawab maupun pelayanan terhadap cargo document, yaitu untuk mengurus dokumen-dokumen kapal yang habis masa berlakunya, pelayanan terhadap segala sesuatu yang berhubungan dengan kedatangan kapal sampai keberangkatan kapal dan memberikan pelayanan terhadap kelengkapan dokumen muatan yang akan diangkut. Dan penyebab terjadinya keterlambatan kapal keagenan PT. Indo Dharma Transport cabang Surabaya karena faktor cuaca yang tidak terduga.

Kendala dalam pengurusan dokumen clearance pada instansi yang terkait disebabkan kurang profesionalnya pelayanan yang diberikan pada pengguna jasa sehingga menghambat keberangkatan kapal.

\section{DAFTAR PUSTAKA}

BPKP. (2010). Peraturan Pemerintah Republik Indonesia Nomor 20 Tahun 2010 Tentang Angkutan di Perairan.

Fatah, A., Sukiman, \& Fathurachman, E. R. (2019, November). Peranan Perusahaan Pelayaran dalam Rangka Kelancaran Pengurusan Perpanjangan Sertifikat Kapal di Pelabuhan Merak Banten. Jurnal Sains Teknologi Transportasi Maritim, 1(2), 25-30.

Haris Herdiansyah. (2010). Metodologi Penelitian Kualitatif. Jakarta: terbitan Salemba 4.

Hutabarat, R. (1996). Transaksi Ekspor Impor. Erlangga.

Komalasari, Y. (2020). Analysis of Ship Document Management by PT. Lintas Samudera Borneo Lines at One Stop Service Center. Excellent Human Resource for the Sustainable Safety of Inland Water and Ferries Transport in New Normal Era-International Webinar (IWPOSPA 2020) (pp. 468-480). KnE Social Sciences.

Kosasih, E. (2012). Manajemen Keuangan Akuntansi

Perusahaan Pelayaran: Suatu Pendekatan Praktis dalam Bidang Usaha Pelayaran. Raja Grafindo Persada.

Lasse. (2014). Manajemen Kepelabuhan. Raja Grafindo Persada.

Mandala, E., Setyadiharja, R., Jefri, Renaldi, R., \& Mulyani, N. (2016, September). Implementasi Kebijakan tentang Penerbitan Surat Persetujuan Berlayar (SPB) (Studi Kasus di Kantor Syahbandar dan Otoritas Pelabuhan Kijang). Jurnal Ilmu Pemerintahan: Kajian Ilmu Pemerintahan dan Politik Daerah, 1(2), 247-264. 
Rubiyanto, A. (2017, Februari). Peranan

PT.Kharisma Indah Lestari Shipping sebagai Perusahaan Keagenan dalam Menangani Kedatangan Kapal di TG.Emas Semarang. Gema Maritim, 19(1), 91-103.

Sasono, H. B. (2012). Manajemen Pelabuhan dan Realisasi Ekspor Impor. Andi.

Sugiyono. (2015). Metode Penelitian. PT Alfamida JML.
Sutopo. (2002). Metodologi Penelitian Kualitatif. PT. Sebelas Maret Univesity Press.

Suwarno. (2011). Manajemen Pemasaran Jasa Perusahaan Pelayaran (Era Globalisasi). Badan Penerbit Universitas Diponegoro. 